\title{
Synthesis and Characterization of Proton-Conducting Oxides as Hydrogen Transport Membranes
}

\author{
Lin Li and Enrique Iglesia \\ Department of Chemical Engineering, University of California at Berkeley, \\ Division of Materials Sciences, E.O. Lawrence Berkeley National Laboratory, \\ Berkeley, CA 94720
}

The hydrogen permeation properties of dense $\mathrm{SrCe}_{0.95} \mathrm{Yb}_{0.05} \mathrm{O}_{3-\mathrm{x}}$ membranes were examined under various conditions and described based on the conductivities of available charge carriers using a transport model for mixed conductors. The chemical environment on each side of the membrane influences not only the chemical potential driving force for transport but also the conductivities of the various charge carriers. When one side of the membrane is exposed to oxidizing atmosphere, the $\mathrm{H}_{2}$ flux is limited by hole conduction. In reducing atmosphere, $\mathrm{SrCe}_{0.95} \mathrm{Yb}_{0.05} \mathrm{O}_{3-\mathrm{x}}$ membranes show electron conductivity and the electron transference number increases with increasing $\mathrm{H}_{2}$ partial pressure. The hydrogen flux-current behavior during electrochemical pumping is caused by an insulatorsemiconductor transition that occurs with increasing applied voltage.

\section{INTRODUCTION}

Cost-effective reactor and separation technologies based on inorganic membranes can lead to significant economic benefits as components of several strategies for the conversion of natural gas. Oxygen-transport membranes based on mixed conductors are being developed for oxygen purification and for coupling with steam reforming reactions in the production of synthesis gas [1]. Oxides with perovskite structures similar to those of oxygen conductors but with immobile oxygen anions can also exhibit protonic or mixed protonic-electronic conductivity, without significant oxygen transport, in hydrogen or water atmospheres $[2,3]$. Such materials have been less extensively studied than oxygen conductors, but they can be used to extract $\mathrm{H}_{2}$ from streams in the presence of chemical or electrochemical potential gradients. For example, dense perovskite membranes, especially as thin films with high conductivity, can be used to remove $\mathrm{H}_{2}$ continuously from reactors used to carry out reactions with unfavorable thermodynamics. $\mathrm{H}_{2}$ removal during catalytic methane pyrolysis [4] and during steam reforming [5] has been recently suggested in order to increase achievable $\mathrm{CH}_{4}$ conversions in these endoergic reactions. In this paper, we report the synthesis and transport characteristics of dense disk $\mathrm{SrCe}_{0.95} \mathrm{Yb}_{0.05} \mathrm{O}_{3-\mathrm{x}}$ membranes. 


\section{EXPERIMENTAL METHOD}

Combustion methods based on reactions of nitrate groups with metal chelates were used to prepare $\mathrm{SrCe}_{0.95} \mathrm{Yb}_{0.05} \mathrm{O}_{3-\mathrm{x}}$ ceramic powders with unimodal size distributions [6]. The powders were treated in air at $5^{\circ} \mathrm{C} / \mathrm{min}$ to $1000^{\circ} \mathrm{C}$ for $2 \mathrm{~h}$. X-ray diffraction patterns corresponded to the perovskite structure. These powders were then pressed at $142 \mathrm{MPa}$ and sintered in flowing sir at $5^{\circ} \mathrm{C} / \mathrm{min}$ to $1550^{\circ} \mathrm{C}$ for $2 \mathrm{~h}$ in order to obtain dense disks. After sintering, the disk membranes are $20 \mathrm{~mm}$ in diameter, $1 \mathrm{~mm}$ in thickness, and proved free of cracks by $\mathrm{He}$ permeation experiments at room temperature. The density of the sintered membranes were greater than $90 \%$ of the skeletal density,

The hydrogen flux through $\mathrm{SrCe}_{0.95} \mathrm{Yb}_{0.05} \mathrm{O}_{3-\mathrm{x}}$ membranes was measured using a hightemperature permeation apparatus. Gas flow rates in each side of the membrane disks were metered by electronic mass flow controllers (Porter). One side of the membrane was exposed to $\mathrm{H}_{2}$ (Airgas, 99.99\%) diluted to the desired concentration using $\mathrm{He}$ (Airgas, 99.999\%). The opposite side was exposed to $\mathrm{N}_{2}$ (Airgas, 99.999\%) or $\mathrm{N}_{2} / \mathrm{O}_{2}$ (Airgas, 99.6\%). The $\mathrm{H}_{2}$ in the permeate flow was oxidized to water in a hydrogen conversion reactor using a Pt mesh as catalyst, and the hydrogen flux through the membrane was determined by measuring the water concentration using an HMI 38 humidity data processor (Vaisala). When the down side of the membrane was swept by $\mathrm{N}_{2}$, a make-up $\mathrm{O}_{2}$ was introduced in the sweep side in order to convert $\mathrm{H}_{2}$ to water. In order to provide a pathway for electron transport, platinum wires were connected to both sides of membrane using Ag conductor ink (Alfa Aesar). After treating in air at $850^{\circ} \mathrm{C}$ for $0.5 \mathrm{~h}$, the $\mathrm{Ag}$ ink formed a porous electrode layer on the membrane surface. Permeability measurements were performed under both open-circuit and closed-circuit conditions. In addition, electrochemical pumping experiments were carried out by applying a voltage (HP-6334B DC power supply) across the membrane.

\section{MASS TRANSFER MODEL}

In order to interpret experimental hydrogen transport rates, we adapted a transport model for oxygen separation membranes based on non-equilibrium thermodynamic treatments of diffusion processes [7] to proton-electron mixed conductors. By assuming adsorptiondesorption equilibrium at each side of the membrane and protons $\left(\mathrm{OH}^{-}\right)$, electrons (e'), and electron holes $\left(h^{*}\right)$ as the available charge carriers, the $\mathrm{H}_{2}$ flux is given by:

$j_{H_{2}}=\frac{\sigma_{O H} I}{2 \sigma_{T} F}-\frac{\sigma_{O H}\left(\sigma_{h}+\sigma_{e^{\prime}}\right)}{4 \sigma_{T} F^{2}} \nabla \mu_{H_{2}}$

where $\sigma_{k}$ is the conductivity of charge carrier $\mathrm{k}, \sigma_{T}$ is the total conductivity, $\nabla \mu_{H_{2}}$ is the chemical potential gradient of $\mathrm{H}_{2}$, and $\mathrm{F}$ is the Faraday constant.

For open-circuit conditions, the net current across the membrane is zero ( $\mathrm{I}=0)$ and Eq.(1) can be simplified to: 
$j_{H_{2}}=-\frac{\sigma_{O H} t_{e l}}{4 F^{2}} \nabla \mu_{H_{2}}$

where $t_{e l}=\left(\sigma_{h}+\sigma_{e}\right) / \sigma_{T}$ is the electronic transference number. For closed-circuit conditions, the electronic conductivity of the connecting wire is much higher than that of the membrane. Then, the $\mathrm{H}_{2}$ flux is given by:

$j_{H_{2}}=-\frac{\sigma_{O H}}{4 F^{2}} \nabla \mu_{H_{2}}$

In our permeation experiments, the $\mathrm{H}_{2}$ permeation rate is less than $0.1 \%$ of the feed and sweep gas flows; therefore, gas phase compositions on each side of the membrane are similar to those of the respective inlet streams and independent of the nature of the measurement (closed or open circuit). Therefore, $\sigma_{O H}$ and $\nabla \mu_{H_{2}}$ in Eq. (2) and (3) are similar for open and closed circuit conditions. By comparing the hydrogen flux under open and closed circuit conditions, we can obtain the electron transference number:

$t_{e l}=\frac{\left(j_{H_{2}}\right)_{\text {open-circuit }}}{\left(j_{H_{2}}\right)_{\text {closed-circuit }}}=\frac{\sigma_{h^{\prime}}+\sigma_{e}}{\sigma_{T}}$

\section{RESULTS AND DISCUSSIONS}

\section{1 $\mathrm{H}_{2}$ permeation of $\mathrm{SrCe}_{0.95} \mathrm{Yb}_{0.05} \mathrm{O}_{3-\mathrm{x}}$ membrane}

Figure 1 shows the hydrogen flux through the membrane at $950 \mathrm{~K}$ under open and closed circuit conditions when the down side of the membrane is swept by $\mathrm{N}_{2}$. In this situation, both sides of the membrane are exposed to a reducing atmosphere, although $\mathrm{H}_{2}$ partial pressure in the sweep side is very low $(<1 \mathrm{kPa})$. Figure 2 shows the $\mathrm{H}_{2}$ flux when $10 \% \mathrm{O}_{2} / \mathrm{N}_{2}$ mixture was used as the sweep gas (denoted as asymmetric condition). In both cases, the $\mathrm{H}_{2}$ flux increased with increasing $\mathrm{H}$ concentration, but the measured fluxes were significantly higher with the oxidizing sweep gas (Figs. 1 and 2).

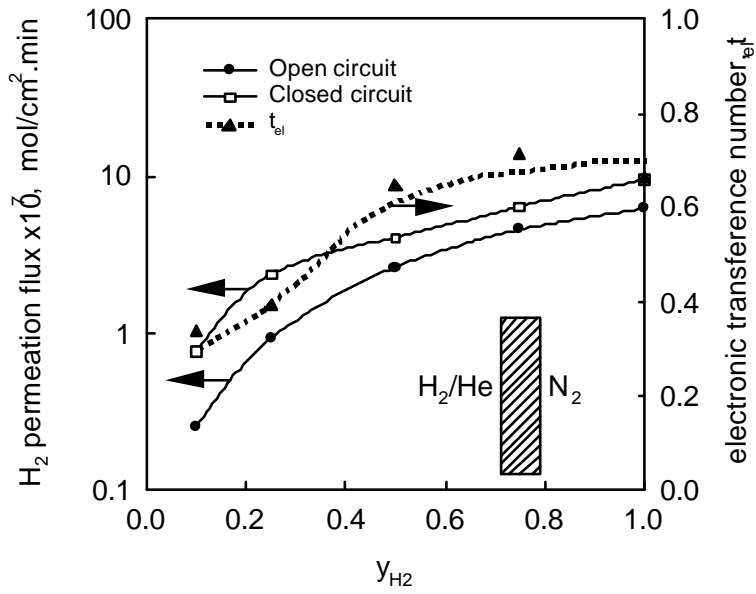

Figure $1 . \mathrm{H}_{2}$ flux under symmetric conditions $\mathrm{T}=950 \mathrm{~K}$

These results show that the chemical environment on both sides of $\mathrm{SrCe}_{0.95} \mathrm{Yb}_{0.05} \mathrm{O}_{3-\mathrm{x}}$ membranes influences hydrogen permeation rates. These effects can be described by considering the concurrent effects of the chemical environment on the permeation driving 
force and on the membrane conductivities and charge carrier concentrations. The changes in charge carrier concentrations reflect the thermodynamic equilibrium for the reactions:

$$
\begin{aligned}
& 1 / 2 \mathrm{O}_{2}+\mathrm{V}_{\mathrm{O}}^{*}=\mathrm{O}_{\mathrm{O}}^{\times}+2 \mathrm{~h} \\
& \mathrm{H}_{2}+2 \mathrm{O}_{\mathrm{O}}^{\times}=2 \mathrm{OH}+2 \mathrm{e}^{\prime} \\
& \mathrm{H}_{2} \mathrm{O}+\mathrm{V}_{\mathrm{O}}+\mathrm{O}_{\mathrm{O}}^{\times}=2 \mathrm{OH}
\end{aligned}
$$

In Eq.(2), $\nabla \mu_{H_{2}}$ is the driving force for mass transfer, and the $\left(\sigma_{O H} \cdot t_{e l}\right)$ can be considered as a resistance to transfer, which is determined by the concentrations and mobilities of charge carriers. When the chemical environment influences only the permeation driving force, Eq. (2) can be integrated with $\left(\sigma_{O H} \cdot t_{l l}\right)$ as a constant. Our symmetric and asymmetric flux measurements, however, show that $\left(\sigma_{O H} \cdot t_{e l}\right)$ deponds on the chemical environment and thus of position within the membrane. It seems, therefore, that a quantitative discussion of the $\mathrm{H}_{2}$ concentration and of the sweep gas identity will require a detailed

description of how $\sigma_{O H}$ and $\sigma_{e l}$ vary with

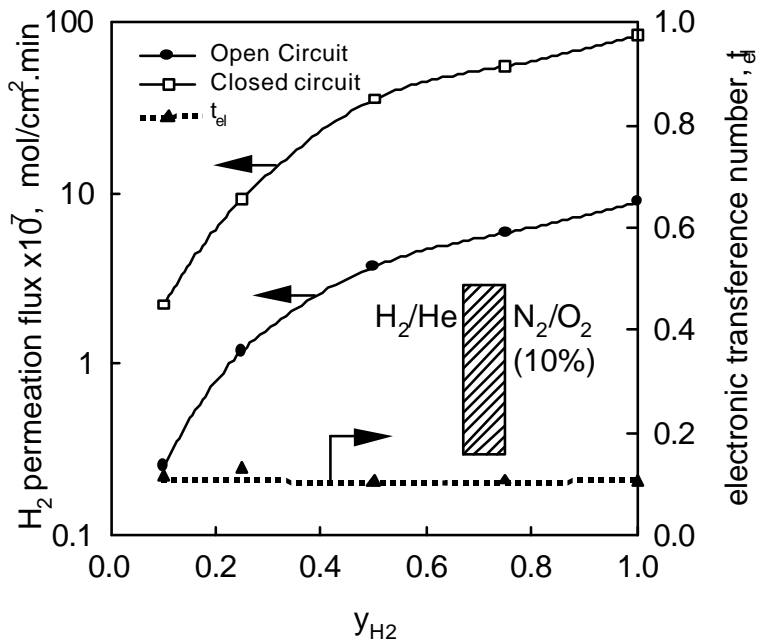

Figure 2. $\mathrm{H}_{2}$ flux under asymmetrical conditions $\mathrm{T}=950 \mathrm{~K}$ chemical environment.

An external circuit led to an obvious increase in $\mathrm{H}_{2}$ flux, suggesting that electron conductivity limits overall hydrogen transport rates. Therefore, further improvement in hydrogen flux will require an increase in the electronic conductivity of the membrane.

\subsection{Electronic transference numbers}

The electron transference numbers $\left(t_{e l}\right)$, calculated from Eq. (4), are shown in Figures 1 and 2. Asymmetric conditions lead to low $t_{e l}$ values $(\sim 0.1)$, which are not influenced by $\mathrm{H}_{2}$ partial pressure. Therefore, hydrogen permeation rates are largely controlled by the ability of the membrane to conduct electrons and to balance the flux of positive charge induced by proton transport.

$\mathrm{SrCe}_{0.95} \mathrm{Yb}_{0.05} \mathrm{O}_{3-\mathrm{x}}$ is an acceptor-doped oxide and its electronic conductivity is influenced by the oxygen activity in the environment [8]. From reaction (5) and (6), we can see that under asymmetrical conditions, the major carriers for electronic conduction are electrons at the reducing side and holes at the oxidizing side. The total electronic conductivity of the membrane will be determined by the lower of all the conductivities at each side of the membrane. With increasing $\mathrm{H}_{2}$ partial pressure, the electronic conductivity in the reducing side of the membrane increases, because of higher electron concentrations, but the electronic conductivity in the oxidizing side remains unchanged because the hole 
concentration is determined by the $\mathrm{O}_{2}$ partial pressure in the sweep gas. The constant electronic transference number as $\mathrm{H}_{2}$ partial pressures varies (Figure 2) indicates that under asymmetric conditions, the electronic conductivity is controlled by the hole conduction in the oxidizing side. This conclusion is consistent with the results of $\mathrm{H}_{2}$ permeation and conductivity measurements reported by Hamakawa et al [9]. Therefore, under this operation mode hole conduction rate must be increased in order to increase electronic conductivity and hence $\mathrm{H}_{2}$ fluxes.

From a practical point of view, both sides of the $\mathrm{H}_{2}$ separation membranes will be exposed to reducing atmospheres. In this situation, we need to maintain electronic conductivity through electron conduction. The electronic transference number results shown in Figure 1 demonstrated that with $\mathrm{N}_{2}$ as the sweep gas, $t_{e l}$ values are significantly higher and they increase with increasing $\mathrm{H}_{2}$ pressure. This is because in reducing atmospheres, $\mathrm{Ce}^{4+}$ can be partially reduced [10,11]; therefore the $\mathrm{SrCe}_{0.95} \mathrm{Yb}_{0.05} \mathrm{O}_{3-\mathrm{x}}$ membrane becomes a better electron conductor.

The increase in $t_{e l}$ with increasing $\mathrm{H}_{2}$ partial pressure indicates that with increasing $\mathrm{H}_{2}$ partial pressure, we increase not only the mass transfer driving force for $\mathrm{H}_{2}$ transport, but also the electronic conductivity of the membrane, both of which have a positive effect on $\mathrm{H}_{2}$ flux. For $\mathrm{SrCe}_{0.95} \mathrm{Yb}_{0.05} \mathrm{O}_{3-\mathrm{x}}$ membranes Hamakawa et al. reported no detectable $\mathrm{H}_{2}$ flux when the downside was swept by Ar and concluded that the membrane behaved as a pure proton conductor [9]. The reason for this is that in their experiments, the $\mathrm{H}_{2}$ partial pressure in the feed was only $1 \mathrm{kPa}$ (vs. $20-100 \mathrm{kPa}$ in this study); therefore the electron concentration was low. From the above analysis, we conclude that the $\mathrm{H}_{2}$ flux is limited by the rate of transport of different charge carriers as the chemical environment changes from reducing to oxidizing.

\subsection{Electrochemical pumping}

The permeation driving force was also varied by applying a direct voltage across the membrane. The $\mathrm{H}_{2}$ permeation rate increased at low voltages, as predicted by Faraday's law [12] (Fig. 4). At higher applied voltages, $\mathrm{H}_{2}$ permeation rates are lower than predicted from theory and the deviation becomes larger with increasing applied voltage, indicating that $t_{e l}$ concurrently increases. At low voltages, the membrane behaves as an insulator, but it becomes a semiconductor as the applied voltage approaches the band gap of the membrane material. At voltages larger than the band gap, the membrane behaves as an

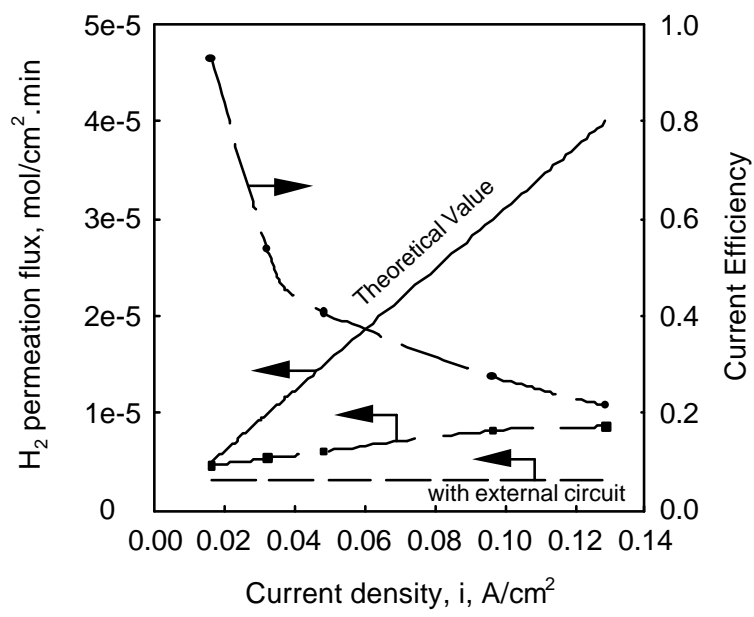

Figure 3. Electrochemical Pumping Results $\mathrm{T}=1000 \mathrm{~K}$ electronic conductor and the contribution of Electronic conduction to the total current becomes larger. Therefore, with increasing current density $i$, the slope of $j_{H_{2}}-i$ plot decreases, and ultimately becomes a horizontal line because of the very high electronic conductivity at high applied voltages. 


\section{CONCLUSIONS}

The hydrogen flux through $\mathrm{SrCe}_{0.95} \mathrm{Yb}_{0.05} \mathrm{O}_{3-\mathrm{x}}$ membrane disks was measured under both open-circuit and closed-circuit conditions, and the hydrogen permeation behavior was analyzed by using a mass transfer model for mixed proton-electron conductor. The change of atmosphere on each sides of the membrane influenced not only the mass transfer driving force for hydrogen transport, but also the membrane transport properties. The increase in hydrogen permeation flux achieved by using an external circuit to provide an additional pathway for electron transfer indicates that the hydrogen permeation rate through the membrane is limited by the electronic conduction within the membrane. By comparing the hydrogen permeation flux under open and closed circuit, the average electron transference number was estimated, and the limiting charge carriers for $\mathrm{H}_{2}$ transport through the membrane were determined. Under asymmetrical conditions, the electronic transference number is only 0.1 and transport is controlled by hole conduction. In reducing environments the electronic transference number is higher, reflecting a higher electron conduction caused by the partial reduction of $\mathrm{Ce}^{4+}$. These results indicate that in order to maintain high electronic conductivity in $\mathrm{H}_{2}$ separation membranes, we must introduce reducible cations in order to enhance electron conduction. By applying an external voltage, the membrane can be operated as an electrochemical pump, and the hydrogen flux-current density behavior can be interpreted by considering the insulator to conductor transition of the membrane as the applied voltage increases.

\section{REFERENCES}

1. U. Balachandran et al., Catalyst Today, 36 (1997), 265-272

2. U. Iwahara, Solid State Ionics, 86-88 (1996), 9-15

3. X. Qi, Y.-S. Lin, Solid State Ionics, 130 (2000), 149-156

4. R. W. Borry, E. C. Lu, Y. H. Kim, E. Iglesia, Stud. Surf. Sci. Catal., 119 (1998), 403

5. T. Terai, X. H. Li, K. Fujimoto, Chem. Lett., 4 (1999), 323-324

6. E. C. Lu, E. Iglesia, Journal of Materials Science, accepted for publication

7. H. J. M., Bouwmeester, A. J. Burggraaf, Fundamentals of Inorganic Membrane Science and Technology, Ed. By A. J. Burggraaf, pp 435-528, Elsvier Science, Amsterdam, 1996

8. D. M. Smyth, Properties and Applications of Perovskite-type Oxides, Ed. By L. G. Tejuca and J. L. G. Fierro, pp47-72, Marcel Dekker, New York, 1992

9. S. Hamakawa, T. Hibino, H. Iwahara, J. Electrochem. Soc., 141 (1994), 1720-1725

10. H. L. Tuller, Nonstoichiometric Oxides, Ed. By O. Toff Sorensen, pp 271-325, Academic

Press, New York, 1981

11. T. Norby, Solid State Ionics, 125(1999), 1-11

12. H. Iwahara, Solid State Ionics, 125(1999), 271-278 